\title{
Revista Colombiana de

\section{Síndrome coronario agudo con supradesnivel del ST asociado al feocromocitoma con las catecolaminas inicialmente normales}

\section{Jorge M. Pacheco*, Gabriel Pérez Baztarrica, Fernando Díaz Bozio, Andrés Jiménez y Rafael Porcile}

Departamento de Cardiología, Cátedra de Fisiología, Hospital Universitario de la Universidad Abierta Interamericana, Facultad de Medicina

Recibido el 6 de febrero de 2015; aceptado el 2 de agosto de 2015

Disponible en Internet el 26 de septiembre de 2015

\section{PALABRAS CLAVE \\ Tumores; \\ Receptores \\ alfa-adrenérgicos; \\ Receptores \\ beta-adrenérgicos; \\ Infarto agudo \\ de miocardio}

\section{KEYWORDS}

Tumors;

Alpha adrenergic

receptors;

Beta adrenergic

receptors;

Acute myocardial

infarction

\begin{abstract}
Resumen Los feocromocitomas son tumores secretores de catecolaminas que cursan con paroxismos de hipertensión o hipotensión arterial y palpitaciones. Son una causa rara del síndrome coronario agudo. Presentamos el caso de una paciente con síndrome coronario agudo secundario a feocromocitoma que inicialmente tenía valores normales de catecolaminas.

(c) 2015 Sociedad Colombiana de Cardiología y Cirugía Cardiovascular. Publicado por Elsevier España, S.L.U. Este es un artículo Open Access bajo la licencia CC BY-NC-ND (http://creativecommons.org/licenses/by-nc-nd/4.0/).
\end{abstract}

Acute coronary syndrome with ST elevation associated with pheochromocytoma with initially normal catecholamine values

Abstract Pheochromocytomas are catecholamine-secreting tumors that involve paroxysmal hypertension or hypotension and palpitations. They are a rare cause of acute coronary syndrome. We present the case of a patient with acute coronary syndrome secondary to a pheochromocytoma with initially normal catecholamine values.

(c) 2015 Sociedad Colombiana de Cardiología y Cirugía Cardiovascular. Published by Elsevier España, S.L.U. This is an open access article under the CC BY-NC-ND license (http://creativecommons.org/licenses/by-nc-nd/4.0/).
* Autor para correspondencia.

Correo electrónico: dr-jmpm@hotmail.com (J.M. Pacheco).

\section{Introducción}

Los feocromocitomas y los paragangliomas son tumores productores de las catecolaminas que aparecen en el 25 - 33\% de 
los casos asociados a síndromes clínicos hereditarios, otros son esporádicos. Se caracterizan por presentar paroxismos de hipertensión arterial y taquicardia. Los feocromocitomas son una causa rara de infarto agudo de miocardio. Presentamos el caso de una paciente que presentó un infarto agudo de miocardio y crisis hipertensivas con valores iniciales de catecolaminas normales que posteriormente fueron elevados y que requirió extirpación de un tumor suprarrenal para resolver la recurrencia de los estados hiperadrenérgicos.

\section{Caso clínico}

Se trata de una mujer de 38 años de edad, que ingresó enviada de otro centro con diagnóstico de síndrome coronario agudo con supradesnivel del ST anterior para realizar cinecoronariografía y eventual angioplastia. Tiene antecedentes de hipertensión arterial desde hace 15 años e hipotiroidismo. Ocasionalmente presenta episodios de palpitaciones, diaforesis y disnea en reposo. Dos meses antes del actual ingreso, en consulta ambulatoria con medicina interna, se solicitó niveles de las catecolaminas y sus metabolitos en la orina, los cuales estaban dentro de valores normales. No tiene otros antecedentes patológicos significativos.
Al ingreso estaba consciente y orientada, con buena mecánica respiratoria. Presentaba: dolor torácico anginoso de intensidad 7/10, FC 110', TA 190/110. Sin datos de relevancia clínica en el resto del examen físico. El electrocardiograma mostró supradesnivel ST DI-AVL y V1 a V3 (fig. 1A).

Tras la administración de nitroglicerina intravenosa, resuelve dolor torácico e isonivela el ST. En ese momento, la CPK fue de $1300 \mathrm{U} / \mathrm{L}$, con MB de $110 \mathrm{U} / \mathrm{L}$ y el ecocardiograma mostraba: diámetro diastólico ventricular izquierdo $50 \mathrm{~mm}$ y sistólico $30 \mathrm{~mm}$, septum $15 \mathrm{~mm}$, pared posterior $11 \mathrm{~mm}$, hipocinesia del septum anterior y de todos los segmentos apicales. Deterioro moderado de la fracción de eyección. Hipertrofia ventricular izquierda, sin valvulopatías.

Se realizó la cinecoronariografía que informa: vasoespasmo coronario difuso, que cede con nitroglicerina intracoronaria. La coronaria izquierda, la descendente anterior, la circunfleja y la coronaria derecha no tenían lesiones angiográficamente significativas (fig. 1 B-c).

Se indicó tratamiento farmacológico con: nitritos, bloqueantes cálcicos, enalapril y estatinas. Nuevo dosaje de las catecolaminas en la orina con resultado de $1266 \mathrm{mcg} /$ 24 horas (VN: $14-110 \mathrm{mcg} / 24$ horas). El valor de AVM fue normal. Una tomografía de abdomen muestra una masa adrenal de $88 \times 52 \mathrm{~mm}$ en su diámetro mayor con zonas de

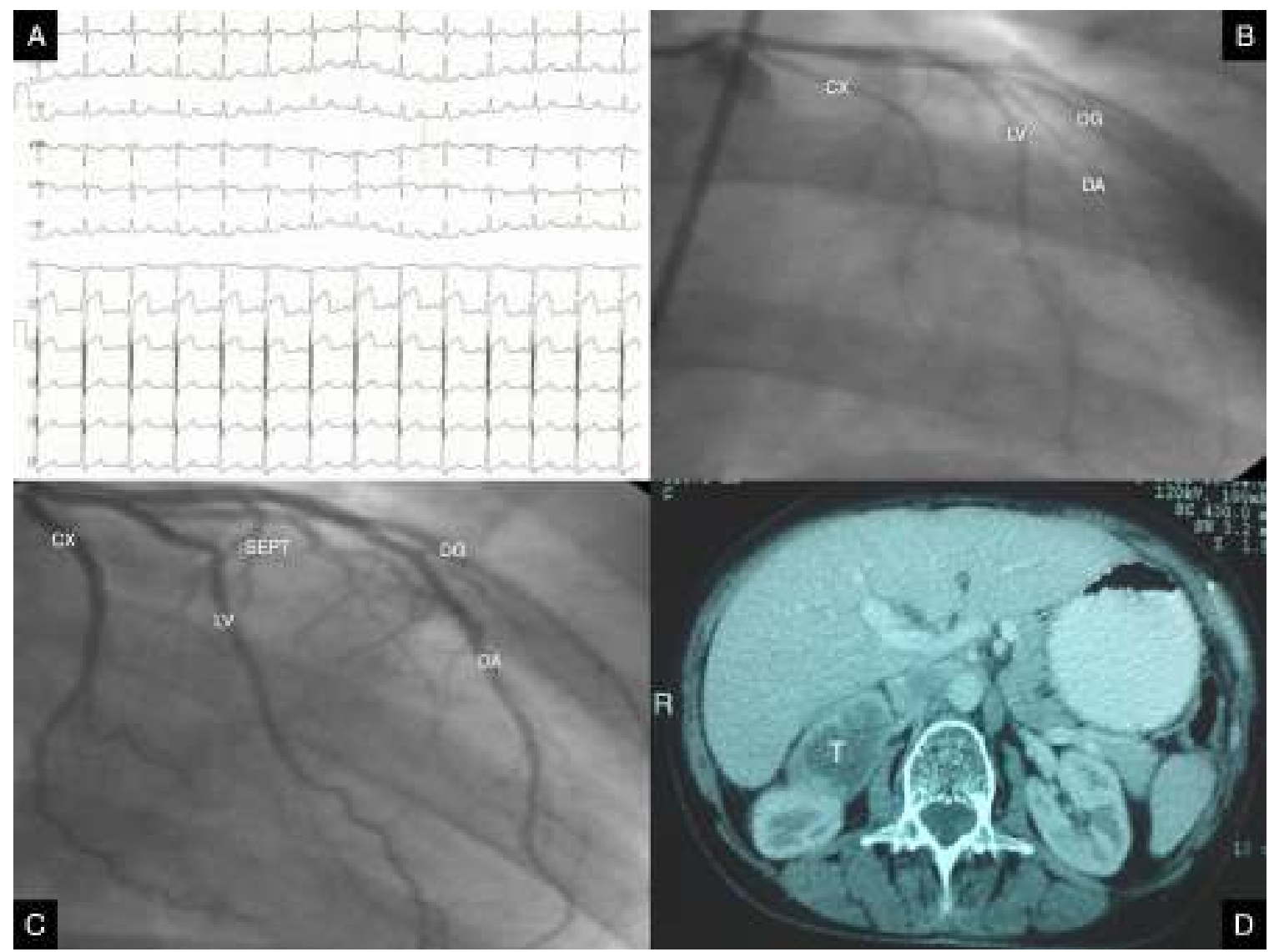

Figura 1 A) Electrocardiograma de ingreso. B) Cineronariografía de la coronaria izquierda en la que se observa vasoespasmo difuso. C) Con la nitroglicerina intracoronaria se observó resolución del espasmo y no se evidenciaron lesiones angiográficamente significativas. D) Tomografía computarizada de abdomen donde se visualizó masa adrenal.

DA: descendente anterior. SEPT: septales. CX: circunfleja. LV: lateroventricular de circunfleja. DG: diagonal. T: tumor adrenal. 
atenuación de < $10 \mathrm{UH}$ (fig. 1 D). Se realizó laparotomía y resección de masa adrenal de 115 gramos, cuyo análisis de anatomía patológica fue positivo para el feocromocitoma. Evolucionó sin recurrencia de hipertensión arterial, ni palpitaciones y sin requerimiento de vasodilatadores.

\section{Discusión}

En la población general, los feocromocitomas aparecen en 2 a 8 personas por 100 mil adultos por año y en promedio 0,05 a $0,2 \%$ de los hipertensos tienen una neoplasia de este tipo. La edad media de aparición es a los 40 años, $10 \%$ son bilaterales, $10 \%$ son extrasuprarrenales y $10 \%$ son malignos. Otras formas de presentaciones aisladas se asocian a diferentes alteraciones genéticas ${ }^{1}$.

Nuestro paciente ingresó por un síndrome coronario agudo asociado a la hiperactividad catecolaminérgica. La isquemia miocárdica en el caso de los feocromocitomas tiene 3 mecanismos. Uno es por el incremento de la masa miocárdica producto de la sobrecarga sistólica ventricular. Los feocromocitomas con predominio en la secreción de noradrenalina, inducen hipertrofia, esta última asociada a la hipertensión ${ }^{2}$. Los otros dos mecanismos incluyen el vasoespasmo coronario y el disbalance entre la oferta y la demanda por taquicardia o taquiarritmias e hipertensión $\operatorname{arterial}^{3}$. Los tres en conjunto pueden llevar al infarto de miocardio, como fue en nuestro caso.

El otro punto que llamó la atención fue el valor inicial normal de las catecolaminas en la orina. Los falsos negativos se pueden explicar analizando el metabolismo de éstas ${ }^{4}$. A partir de la tirosina se produce: dihidroxifenilalanina (dopa), seguida de dopamina, noradrenalina y adrenalina. La inactivación de estos neurotransmisores ocurre por: las enzimas catecol-0-metil transferasa y la mono-amino-oxidasa producidas en el hígado, la actividad de estas enzimas determina la vida media de las catecolaminas y su respuesta fisiológica. La dopamina, la noradrenalina y la adrenalina se excretan en la orina junto con sus metabolitos. En el caso de la adrenalina, la 0-metilación genera metanefrina y la subsecuente deaminación forma ácido vanillilmandélico. El metabolismo de la dopamina produce 3-metoxitiramina seguido de ácido homovalínico. La noradrenalina se convierte en la normetanefrina y el ácido vanillilmandélico.

La cantidad de catecolaminas y metabolitos excretados en la orina dependen de los siguientes factores ${ }^{5}$ :

1. La capacidad del riñón de excretar las catecolaminas y sus metabolitos.

2. Los niveles circulantes de catecol-0-metil transferasa y de mono-amino-oxidasa son habitualmente bajos en las neoplasias cromafines, por lo que los valores de noradrenalina sérica son elevados, no tanto así sus metabolitos.

3. Los tumores menores de 50 gramos tienen rápido recambio de las catecolaminas por lo que se liberan formas no metabolizadas en mayor cantidad que sus metabolitos. Lo contrario ocurre con los tumores mayores de 50 gramos. Es así, como los tumores pequeños exhiben más síntomas.

4. La necrosis tumoral puede asociarse a abrupta interrupción en la secreción de las catecolaminas.
5. La cinética de secreción de las catecolaminas en pacientes con feocromocitoma está íntimamente relacionada con el estímulo simpático fisiológico por situaciones estresantes ${ }^{4}$.

El AVM es el más abundante metabolito en la orina, lo que sugiere que sería el estudio de elección. No obstante, en el feocromocitoma los valores de AVM pueden ser normales y se observa en cambio un aumento de los valores de las metanefrinas o las catecolaminas.

Es por esto que se sugiere realizar la mediciones en la orina en períodos muy cercanos a la crisis, no obstante, algunas veces éstas son muy breves y dificultan la detección del reactante, incluso cuando la recolección de la orina se haya realizado durante la crisis.

Debido a lo raro de esta patología, es probable que los incrementos marginales correspondan a falsos positivos como puede pasar en la respuesta al estrés fisiológico, medicamentos como: la levodopa, el albetalol y los simpaticomiménticos, la clonidina y los tricíclicos en la insuficiencia cardiaca, el shock circulatorio y la hipertensión arterial ${ }^{5}$. La cromogranina A sérica (CgA) se sugiere como alternativa diagnóstica. No se modifica por medicamentos. Su sensibilidad es del $86 \%$ pero tiene poca especificidad. La reducción de la depuración de la creatinina aumenta su valor sérico. Si se combina con las catecolaminas elevadas y un $\mathrm{ClCr}>80 \mathrm{ml} / \mathrm{min}$, su especificidad alcanza el $98 \%{ }^{6}$.

\section{Conclusión}

Nuestra paciente presentó cuadro clínico característico de feocromocitoma. Si bien el dosaje inicial de las catecolaminas y los metabolitos fueron normales, la sospecha clínica obligaba a repetir estudios en busca de un tumor cromafín. En un intento por aumentar la sensibilidad del estudio a costa de sacrificar la especificidad, se debería solicitar tanto los metabolitos finales como los intermediarios y los valores de las catecolaminas por separado en el suero y en la orina y esto hacerlo en varias ocasiones dándole prioridad a los períodos de crisis y postcrisis. Se debe tener presente que algunos feocromocitomas cursan con la hipotensión. Por último, realizar estudios de imágenes anatómicas y funcionales cuando los laboratorios fuesen positivos o si fuesen negativos pero con sospecha clínica alta ${ }^{7}$.

\section{Responsabilidades éticas}

Protección de personas y animales. Los autores declaran que para esta investigación no se han realizado experimentos en seres humanos ni en animales.

Confidencialidad de los datos. Los autores declaran que en este artículo no aparecen datos de pacientes.

Derecho a la privacidad y consentimiento informado. Los autores declaran que en este artículo no aparecen datos de pacientes. 


\section{Conflicto de intereses}

No tenemos conflictos de revelar cualquier relación comercial, financiera, personal o de otra índole con otras personas $u$ organizaciones que puedan influir indebidamente en nuestro trabajo.

\section{Agradecimiento}

Se agradece la participación en la elaboración de este artículo a Gabriela Ciccelli y a mi padre, Guillermo Pacheco Pacheco por su constante apoyo y educación.

\section{Bibliografía}

1. Bernal C, Alacazar J. Feocromocitoma: presentación clínica. Diagnóstico y tratamiento. Hipertensión. 2006;23:173-83.
2. Galetta F, Franzoni F, Bernini G, Poupak F, Carpi A, Cini G, Tocchini L, Antonelli A, Santoro G. Cardiovascular complications in patients with pheochromocytoma: A mini-review. Biomedicine \& Pharmacotherapy. 64:505-509.

3. Yebra M, Asenjo R, Arrue I, Yepes M, Bastante Valiente M, Prieto S. Isquemia miocárdica aguda y trombosis ventricular asociada a feocromocitoma. Rev Esp Cardiol. 2005;58:598-600.

4. Zuber SM, Kantorovich V, Pacak K. Hypertension in Pheochromocytoma: Characteristics and Treatment. Endocrinol Metab Clin North Am. 2011;40(2):295-311.

5. Bravo E. Pheochromocytoma: current perspectives in the pathogenesis, diagnosis, and management. Arq Bras Endocrinol Metab. 2004;48:746-50.

6. Karagiannis A, Mikhailidis D, Athyros V, Harsoulis F. Pheochromocytoma: genetics and management. Endocrine-Related Cancer. 2007; 14:935-56.

7. Caruso G, Brescacin L, Gonzalez S, Gioseffi L. Feocromocitoma con catecolaminas reiteradamente normales. Rev Argent Cardiol. 1999;67:805-7. 